\title{
Correction to: Chest $x$-ray severity score in COVID-19 patients on emergency department admission: a two-centre study
}

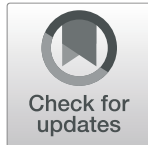

Cristian Giuseppe Monaco ${ }^{1}$, Federico Zaottini ${ }^{2}$, Simone Schiaffino ${ }^{1 *}$, Alessandro Villa ${ }^{2}$, Gianmarco Della Pepa ${ }^{3}$, Luca Alessandro Carbonaro ${ }^{1}$, Laura Menicagli ${ }^{1}$, Andrea Cozzi ${ }^{4}$, Serena Carriero ${ }^{3}$, Francesco Arpaia ${ }^{3}$, Giovanni Di Leo ${ }^{1}$, Davide Astengo ${ }^{2}$, llan Rosenberg ${ }^{2}$ and Francesco Sardanelli ${ }^{1,4}$

Correction to: Eur Radiol Exp 4, 68 (2020)

$$
\text { https://doi.org/10.1186/s41747-020-00195-w }
$$

The original article [1] mistakenly omitted a declaration of competing interests. An appropriate statement can be viewed ahead:

\section{Competing Interests}

Francesco Sardanelli is the Editor-in-Chief of European Radiology Experimental; for this reason, he was not involved in any way in the revision/decision process, which was completely managed by the Guest Editor, Prof. Akos Varga-Szemes (Medical University of South Carolina, Charleston, SC, USA).

\footnotetext{
Author details

'Unit of Radiology, IRCCS Policlinico San Donato, Via Rodolfo Morandi 30, 20097 San Donato Milanese, Italy. ${ }^{2}$ Unit of Radiology, Ospedale Lavagna, Via Don Giovanni Battista Bobbio 25, 16033 Lavagna, Italy. ${ }^{3}$ Postgraduate School in Radiodiagnostics, Università degli Studi di Milano, Via Festa del Perdono 7, 20122 Milan, Italy. ${ }^{4}$ Department of Biomedical Sciences for Health, Università degli Studi di Milano, Via Luigi Mangiagalli 31, 20133 Milan, Italy.
}

Published online: 14 April 2021

\section{Reference}

1. Monaco CG et al (2020) Chest x-ray severity score in COVID-19 patients on emergency department admission: a two-centre study. Eur Radiol Exp. 4:68. https://doi.org/10.1186/s41747-020-00195-w

\footnotetext{
The original article can be found online at https://doi.org/10.1186/s41747020-00195-w.

* Correspondence: schiaffino.simone@gmail.com

'Unit of Radiology, IRCCS Policlinico San Donato, Via Rodolfo Morandi 30, 20097 San Donato Milanese, Italy

Full list of author information is available at the end of the article
}

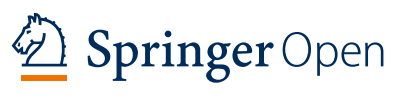

(c) The Author(s). 2021 Open Access This article is licensed under a Creative Commons Attribution 4.0 International License, which permits use, sharing, adaptation, distribution and reproduction in any medium or format, as long as you give appropriate credit to the original author(s) and the source, provide a link to the Creative Commons licence, and indicate if changes were made. The images or other third party material in this article are included in the article's Creative Commons licence, unless indicated otherwise in a credit line to the material. If material is not included in the article's Creative Commons licence and your intended use is not permitted by statutory regulation or exceeds the permitted use, you will need to obtain permission directly from the copyright holder. To view a copy of this licence, visit http://creativecommons.org/licenses/by/4.0/. 